5
Psychiatry

Children are increasingly exposed to unpredictable disaster events that create significant consequences for their physical, psychological, emotional, and social health, which can in turn affect developmental trajectories and extend into adulthood. They are being born into an ever more complex world where the built environment and its surrounding "nature" is a second nature, engineered or unintentionally modified by human activity. The ensuing loss in access to natural environment can have consequences for children's development and their

Ben Wisner

bwisner@igc.org

1 University College London, 373 Edgemeer Place, Oberlin, OH 44074, USA

2 Charles Darwin University, Darwin, Australia

3 University of Melbourne, Melbourne, Australia

4 Western Washington University, Bellingham, WA, USA understanding of how their relationship with the natural environment affects their exposure to hazards [1,2]: due to such misunderstanding, a child in Scotland resisted flood evacuation due to fear of sharks in the dark flood waters [3].

Children are growing up in a new era of earth history: the Anthropocene. This techno-social world is more hazardous due to many compounding changes. Urbanization, climate change, economic globalization, inequality, and austerity interact in complex ways. The home, school, and neighborhood can no longer be considered "safe." Though never isolated from the impact of hazards and failed infrastructure, increasingly home, family, neighborhood, and community are increasingly less self-reliant and resilient.

The purpose of this review is to explore how best to communicate with children and families about the range of hazards that could disrupt their lives and how to be pro-active in age-appropriate ways to protect themselves and those around them. Communication modalities, content, and situation will differ according to the temporal framing or disaster stage. Communication beforehand, with a view to reducing potential impacts and becoming prepared, will differ from communication during the warning, evacuation, immediate response, relief, and recovery stages. The challenge is to communicate in a manner that does not merely transmit 
information or give instruction, but also facilitates communication among family members and within a neighborhood or community. Preparedness for disruption, loss or displacement, and resilience in the face of such impacts requires coproduction of strategies and collective action involving children, families, communities, civil society organizations, and local government. In this context, children should and can be empowered to participate as agents of change. The review also discusses recent literature on how best to communicate with children without producing anxiety and strategies that have been developed for lay people and professionals to communicate with children who have experienced disasterrelated trauma and loss.

While there is currently no overarching agreement on either theory or intervention strategies for working with children, it is increasingly evident that theory and intervention strategy development should include not only the child but also the family and the school as well as the wider socio-cultural context and environmental settings in which interaction regularly occurs $[4 \bullet, 5,6,7 \bullet]$. The dynamic interaction across these domains will affect the development and application of adaptive capacity and the rate and quality of response to disaster. Furthermore, the development of these frameworks should adopt child-centered approaches that acknowledge the fundamental right of children to have agency in their own lives [4•, 5,8 ], with this approach being better suited to understanding and addressing social justice issues and to exploring strategies to empower children, such as by adopting a citizenship in action approach [4•].

\section{Communicating With Children}

Communication with children should not be one-way. Children have perceptions and ideas and should be interlocutors, not the object of top-down instruction. Roger Hart was one of the first to lay out systematically an approach to treating children and youth as agents and participants in understanding and planning their surroundings [9]. His work was taken on board by UNICEF [10] and became much used, as he observed in a retrospective essay [11]. UNICEF developed this participatory approach to working with children as did the "Child in the City" project $[12,13]$. Participatory work with children must be voluntary and personal, as well as interactive and responsive. These four adjectives are at the core of ethical considerations in communicating with children however they are chosen and whatever formal, professional ethics protocols are used [14]. Furthermore, Lundy [15•] asserts that children's participation is implied by the UN Convention on the Rights of the Child.

It is important to listen to children and youth where there may not be a formal setting or forum such as a school. The gender of children and youth is often overlooked in well- intentioned efforts at listening. The Inter-Agency Standing Committee, the international reference group for humanitarian assistance, published the second edition of its Gender Handbook for Humanitarian Action [16]. This very valuable resource has discussions of children and youth incorporated into its sections on "Needs Assessment" (pp. 30-43), "Participation" (pp. 84-87), "Education" (pp. 168-197), and "Protection" (pp. 298-323). In addition, the international nongovernmental organization, PLAN International has published a thorough report on adolescent girls in disaster and refugee camp situations [17]. Fothergill and Peek [18•] followed 650 children after Hurricane Katrina. The long annex in this book on methodology is an extremely useful guide to putting compassion into practice in discussing disasters with children and youth.

\section{Communicating With Children in School}

Depending on age, level of social-cognitive development, level of literacy, and access to materials and technology, many methods and media may be used to communicate with children and to co-produce knowledge of hazards and ways to reduce risk. Kitagawa [19] places disaster education in the broader context of safety training as these have evolved in Japan over the past few decades. One method of note that arose in Japan and has spread elsewhere is "townwatching." This is an exercise in which children physically walk through the built environment with guides and discuss and later map and write about hazards as risk reduction. This method is based on earlier attempts in the 1960s and 1970s to democratize the government's formerly top-down physical planning [20], was adopted during the reconstruction of Kobe after the 1995 earthquake [21], and continues to be widely used in Japan [22]. Town-watching has broadened to include mountain-watching and coast-watching and has inspired international guidelines provided by the UN Secretariat for Disaster Reduction [23] and similar approaches in Vietnam, Malaysia, India, China, and Taiwan [24]. In addition, comic books, board games, video games, three-dimensional mapping, and many other methods and media are applicable [25-27].

\section{Children and Youth as Communicators and Actors}

The Sendai Framework for Disaster Risk Reduction 20152030 [28] calls for the involvement of children and youth in planning for disaster risk reduction:

Children and youth are agents of change and should be given the space and modalities to contribute to disaster 
risk reduction, in accordance with legislation, national practice and educational curricula... (p. 23).

Children and youth play an important role in bringing disaster risk awareness home with them from school, encouraging their families to make plans and take preparedness, and communicating more widely in their communities [29, 30]. Two examples are a training program called Teen SERT that has been developed for US high schools and flood activism in England. SERT teaches basic skills such as light fire suppression, light search and rescue, first aid, transportation of the injured, communication, and leadership, similar to the curriculum of Community Emergency Response Training (CERT) common in many parts of the USA [31]. Thus, school-based training may be applied in the community. Mort and colleagues studied flood-affected youth in England [32•], identifying ways that they could be better supported and also how their experience can help to shape flood management policy. The youth themselves wrote a "Manifesto" asserting the importance of including youth in planning and pointing out their previous absence. Fothergill cites a number of cases in which youth have been directly engaged in relief and recovery [33].

Ronan and co-authors review a large number of childcentered disaster risk reduction and resilience (CC-DRR) programs [34•]. Another review of youth participation as well as disaster education in schools concluded that the former tended to focus more deeply on the root causes of disaster than school-based programs and continued with the following recommendation $[35$, p. 8$]$ :

Notably, several of the papers on children's participation in DRR [disaster risk reduction] were published as a result of collaborations between NGOs and academia. From this perspective, new tools and approaches have emerged in CCDRR [child centred disaster risk reduction] practices and evidence on the impact of children's participation documented. Due to these positive outcomes, it is recommended that this type of collaboration should be maintained and replicated to deliver more positive outcomes for children that are conducted directly with those who deliver a large percentage of the programs, e.g. NGOs.

A recent review of literature on child and youth participation in disaster management concludes that besides social and educational benefits young people's activities can have a range of positive psychological benefits [36, p. 5]:

Participation yields numerous potential benefits for children, including enhanced personal development and skills, self-efficacy, and interpersonal relationships, and for communities through improved social connections and networks and disaster preparedness.
Communicating With Children and Families in Post-disaster Situations

Regarding recovery settings, [4•] highlights how the strategies adopted by schools can be diverse. They include child-at-risk (child as victim and passive and in need of protection, potentially including emotional contagion from family settings, child insulated from community settings/involvement, removal from disaster context, no or minimal discussion of disaster at home, parents discouraging discussion of disaster), developing child (schools adopted a participatory, developing-child approach and provided diverse strategies for students to process experiences, creating a sense of shared fate and facilitated putting the events into a wider (development and social) context [8], and citizen child (develop capacity and opportunity to empower students by facilitating collective action in ways consistent with social justice) approaches.

\section{Family Support}

The potential for disasters to create prolonged disruptions to family and support networks can produce repercussions throughout childhood development and on into adult lives [37•]. However, not all impacts have negative consequences [38], and not all children are overwhelmed by disasters [39]. Neither children's exposure, nor their reactions to disasters are homogenous, and this needs to be considered when conceptualizing and researching children's adaptive capacity and resilience [40]. The variation in children's reactions to disasters and the limited research focused on children's own experiences introduces the need for a more detailed assessment of children's experiences of coping and how their positive and negative adaptations are influenced by their social ecological contexts (e.g., family dynamics).

Mooney et al. (in prep) identified multiple resources in the children's immediate family context of parents, siblings, extended family, and pets that appeared fundamental to their capacity to cope and adapt. They reported that children were enabled by others' effective coping and coping assistance, protection, reassurance, and re-establishment of routines and stability fostered children's adaptive behaviors. Parenting that was flexible and sensitive to children's changing needs was found to scaffold children's capacity to cope with earthquake events and consequences. Their findings support arguments that family relationships, particularly parental relationships, facilitate children's capacity to cope effectively with a disaster and suggest the importance of interventions that support parenting and family endeavors during a post-disaster period. In this context, parents can both help and hinder their child's post-disaster coping (Table 1).

Children, especially younger children, look to their parents for cues of how to act. How parents function before, during, and after the disaster has significant influence on how children 
Table 1 From Mooney et al., in prep (Parental Influence on Coping and Adaptation)

\begin{tabular}{|c|c|}
\hline $\begin{array}{l}\text { Parental role in supporting effective coping and } \\
\text { adaptation }\end{array}$ & $\begin{array}{l}\text { Parental role in inhibition of effective coping and } \\
\text { adaptation }\end{array}$ \\
\hline \multirow[t]{2}{*}{$\begin{array}{l}\text { - Coping assistance through modeling, coaching, and } \\
\text { teaching effective coping }\end{array}$} & $\begin{array}{l}\text { - Coping assistance through modeling, coaching, and } \\
\text { teaching ineffective coping such as withdrawal } \\
\text { and ineffective emotional regulation (e.g., panic) }\end{array}$ \\
\hline & - Lack of coping assistance \\
\hline \multirow[t]{2}{*}{ - Protection, buffering, reassurance } & - Lack of protection, buffering, reassurance \\
\hline & - Overprotection \\
\hline \multirow{2}{*}{$\begin{array}{l}\text { - Increased parental awareness: watchful awareness, } \\
\text { acceptance of disaster-related changes in behavior, } \\
\text { positive appraisal, and active involvement of child in } \\
\text { disaster response/preparation }\end{array}$} & $\begin{array}{l}\text { - Limited parental awareness of child's feelings, } \\
\text { disaster-related behavior, or needs }\end{array}$ \\
\hline & $\begin{array}{l}\text { - Over-watchful awareness mainly focused on } \\
\text { detecting trauma symptoms }\end{array}$ \\
\hline $\begin{array}{l}\text { - Providing stability, routines, and distraction so as to } \\
\text { "get on" }\end{array}$ & $\begin{array}{l}\text { - Inability to get on, or provide sufficient stability, } \\
\text { routines, or distraction }\end{array}$ \\
\hline
\end{tabular}

respond [41]. Knowledge of just how family elements in the children's immediate context support effective coping is limited [6].

Studies investigating children's experience from their own reports are rare [42]. Most of the research with children is about them or for them, rather than with them. Nevertheless, research suggests that children can be articulate and informed participants [4•]. There is a need for research that listens to children's own voices [43].

Research suggests that children's resources and external elements promoting resilience (e.g., parent's coping assistance) can interact in a cumulative or additive manner [44]. Coping socialization occurs throughout childhood, but a disaster situation creates complex demands that present multiple possibilities for coping assistance from parents [45]. This assistance can occur through modeling. In the interactive parent/ child relationship, many parents model a calm response to earthquakes and used problem-solving to manage consequences [5].

Children who are helped by their parents in ways that facilitate their ability to process information about disaster experience have better adjustment [46] and are more able to use coping strategies when they perceive such help is available to them. Parents who are more aware of their children's needs enhance capacity in the children to adapt after disaster [41]. However, some parents underestimate the distress of children in post-disaster situations [47] or do not seek assistance from professionals or peers when their children are experiencing distress [48].

Parental assistance and responsiveness is affected by the level of well-being of parents. Parents experiencing high distress are less able to re-establish stability, focus on moving forward, or offer support [49, 50]. However, if parents are coping well themselves, this can, by teaching or modeling effective coping skills in a flexible way, and by maintaining equilibrium through routine and regulation, facilitate children's capacity to adapt following disaster [51•]. In doing so, they re-establish a sense of safety and calming, encourage self-efficacy and connectedness, and provide hope that children and family could one day "get on" from the disaster.

McNeill and Ronan [52] examined whether family constitution, particularly regarding the presence of children of different (very young, young, or teenage children) ages, influenced disaster preparedness. They found that households with young (under twelve years old) and very young (under six years old) children prepared less for wildfires compared with their childless counterparts at the start of the wildfire season, but they had caught up in property preparedness by the end of it. Households with younger children performed fewer disaster-planning actions than childless households. Moreover, they reported lower motivation to prepare, greater perceived difficulty in preparing, and having less time to prepare than childless households. They discussed how these findings reflect the younger age of the adult parents rather than the presence of younger children per se.

Findings support research highlighting the importance of secure attachment relationships for children [53], and that the experience of disaster may increase the bonds in the family system [54], when the family system is functioning well in the disaster context. The family and parents within the family system is a key in fostering their children's responses (e.g., [55]). This signals the importance of interventions to support parenting endeavors during a challenging disaster period. As parents' capacities to support their children appear connected to their own stress level, it is important to provide supportive interventions to parents in a difficult situation and target additional support to those parents who are highly affected by the disaster situation. Other members of the family, for example siblings, also appeared to affect the children's coping and adaptation.

Sibling relationships can affect disaster experience in a positive or negative way [5]. With siblings, children could observe a diverse range of responses. Siblings acted as a potential source of mutual support when the family was 
functioning effectively as a group system and siblings could "stand-in" for absent parents. Hakvoort and co-authors [56] report on the compensatory effect of one warm supportive relationship, such as a sibling relationship, which can have a positive spill-over effect onto other relationships within a family system.

Carpenter and others [57] examined event-related household discussions among area families $(N=460$, ages 4-19) during the 2013 Boston Marathon bombing and subsequent shelter-in-place warning, as well as links between types of household discussions and child post-traumatic stress (PTS). Results generally endorse the importance of open, reassuring, and reciprocal communication with caregivers. Alternatively, avoiding event-related discussion around children, and not reassuring their safety was associated with adverse outcomes. Among results, the authors found:

- There was considerable heterogeneity in household discussions.

- After controlling for child's direct exposure to the potentially traumatic attack/manhunt events, children showed lower PTS when it was their caregivers who informed them about the attack and manhunt, and when their caregivers expressed confidence in their safety and discussed their own feelings about the manhunt with their child.

- Children showed higher PTS when their caregivers did not discuss the events in front of them, asked others to avoid discussing the events in front of them, and expressed concern at the time that their child might not be safe.

- Child age and traumatic attack/manhunt exposure moderated several links between household discussions and child PTS.

Similar results were found by [47] in a cross-national review of family and social factors that influence children's reactions to different types of disasters. Although some of the identified factors do not directly address the topic of "communication with children and families in postdisaster situations," many are likely to have some bearing on communication. For example, positive maternal-child relationship offset adverse outcomes in adolescents (Sri Lanka tsunami impact, 2004); child-parent conflict contributed to increased post-traumatic stress disorder ((PTSD) Hurricane Katrina, 2005); and parents supporting coping strategies led to less adolescent distress and vice versa (September 11th Attack, 2001). Child's perception of attachment to mothers and perceptions of mothers parenting style influenced child anxiety (Hurricane Katrina); parental support for maintaining routines linked to better outcomes while parental restrictions linked to greater functional impairment and PTSD symptoms (Israeli adolescents exposed to terrorism); evidence for cultural differences in influence of parenting style (e.g., authoritarian and permissive maternal parenting styles linked to greater distress in Jewish children, but benefitted Arab children). The remaining discussion focuses on social factors, especially the negative effect of disaster-related media exposure. Child peer support has a protective role (Hurricane Katrina). There are also benefits of providing social support to others (21 months after a flood in a Polish town). High school support buffered the relationship of witnessing community and terrorist violence with violent behavior (Israeli adolescents).

Research in countries where pets are part of the family culture, as in the present study context, has suggested that loss of pets may affect children's response and recovery from disasters [38], and suggested the importance of the animalhuman bond, demonstrated by the number of people who refuse to evacuate during a disaster if they cannot take their pet [58].

\section{Psychological First Aid}

Trethowan and Nursey [59] review a two-phase intervention program designed to provide schoolteachers with knowledge and skills to help young people recover in the wake of the devastating 2009 Victorian bushfires. After consulting child and adolescent trauma experts and the Department of Health and Human Services, the Victorian Department of Education adapted two US programs to train teachers in child support and recovery following a disaster. This resulted in a two-phase program. The first was "Psychological First Aid and Mental Health First Aid: A Guide for Teachers." This was delivered in face-to-face training sessions to teachers in bushfire-affected regions. Training emphasized to teachers that some children will need more help than they can provide and that their role is not to replace mental health professionals. Phase 2 involved online delivery of "Skills for Psychological Recovery" designed as a classroom teaching aid to foster resilience and coping skills. Programs were tailored to different age levels. Teachers were encouraged to maintain appropriate boundaries and reminded that their role should not constitute a counseling role. They were trained to identify young people at high risk and needing professional support, and they were encouraged to involve parents. This online material has been available online to all primary and secondary schools in Victoria since late 2012 and had been completed by four hundred teachers as of October 2015. The authors conclude by recommending a "systematic roll out and evaluation of the program's capacity to successfully support teachers, children and adolescents in the post-recovery period" $[59$, p. 20$]$.

Eifling and Moy [60] provide an evocative article reviewing the current evidence base (as of 2015) for the use of psychological first aid (PFA) during disaster response. The authors begin by pointing to the number of historical examples where posttraumatic responses have been medically misunderstood (e.g., 
soldiers heart, shell shock). They go on to explain how critical incident stress debriefing emerged during the cold war era, which went on to become a dominant model of care offered following trauma, until research established that it was unhelpful and ultimately increased the one-year risk of PTSD following trauma. In their review of the evidence for PFA, the authors identified three high-quality systematic reviews, the most recent one being by Dieltjens and colleagues [61 ${ }^{\bullet}$. None of these reviews were able to identify any rigorous trials with clear evidence for or against the use of PFA. The author's note that this lack of experimental evidence is "extraordinary" when considering how prominently PFA features in many international guidelines. Rather than experimental evidence, the authors find that "the whole family of PFA guidelines" is based "on the wealth of psychological and neurobiological science" and therefore such guidelines "seem reasonable, reality-driven and worthwhile" [60, p. 34].

Vernberg and colleagues [62] discuss how strategies for positive psychology can be used to improve mental health outcomes for children and adolescents during all stages of disaster preparedness, crisis response, and recovery. It identifies three important developmental considerations for positive psychology application: (1) using of age-appropriate language and concepts (e.g., consider reading level for presented material); (2) addressing typical age-related needs and concerns (e.g., needs of toddler vs. adolescences); and (3) employing positive psychology strategies in naturally occurring and developmentally relevant settings (e.g., importance of school). The authors go on to explain in rather general terms how positive psychology can be infused into "5 Essential Elements of Disaster Mental Health" (cf. [63]), which they list as (1) promotion of a psychological sense of safety; (2) promotion of calm; (3) promotion of a sense of self-efficacy and collective efficacy; (4) promotion of connectedness; and (5) instilling hope. They finish with two interesting case studies demonstrating the use of such strategies.

Pfefferbaum's team [64.] provided a review of postdisaster interventions and found that no empirical studies of psychological first aid delivered early in the postdisaster phase can be identified. Very few mental health interventions for children in the early post-disaster phase have been evaluated. Interventions within three months of the event were included in the review. Eleven publications met inclusion criteria, four of which were randomized control trials. Sixteen interventions were implemented in the eleven selected publications. Interventions included cognitive behavioral therapy, narrative exposure, meditation relaxation, debriefing, and eye movement desensitization and reprocessing. Positive outcomes were noted for various outcomes including post-traumatic stress disorder cases and post-traumatic stress symptoms, depression, anxiety, and functioning.

\section{Conclusion}

As most disaster research has focused on children's trauma and symptomology, rather than on investigating processes that enable children to respond adaptively within their social and environmental contexts, our understanding of how children cope effectively and adapt well to disasters is incomplete and an infrequently researched area [47]. While it is evident that many children can demonstrate positive adaptive outcomes when facing adversity [65], neither the specific underlying processes nor how their ecological contexts (e.g., family, peers, school) interact over time to influence coping and adaptive processes are well understood. To this can be added a need to understand how growing up in the Anthropocene is likely to affect children. More work is needed to understand two implications in particular of growing up in cities during this period of Earth history: growing separation from nature and exposure to urban environmental hazards. More research is also needed on how children actively contribute to disaster risk reduction and response. We can learn from the town/mountain/coastwatching examples discussed above to highlight a need to include interacting in the natural environment and its implications for well-being and environmental cognition in future work. To understand positive adaptation, it is as important to examine elements that support positive adaptation as it is to investigate trajectories towards negative adaption and psychopathology [66].

Coping research is still evolving and has yet to conceptualize a developmental framework for children's coping, or to fully develop a model of children's coping within disasters [47]. Children's coping capacities depend in part on the resources available to them (e.g., [67]). These may be internal (e.g., self-efficacy) or external (e.g., family systems, social support networks) resources in the children's contexts. Children are dependent on and interact in space and time with the proximal systems operating in their social and physical environment [68], developing resiliency processes while nested within their cultural context of multiple proximal ecologies: family, school, and neighborhood [5, 7•]. Children's capacities to adapt and cope are thus affected by the contexts in which their development occurs. Of primary importance are the children's family systems and their relationships with their parents.

\section{Compliance with Ethical Standards}

Conflict of Interest Ben Wisner, Douglas Paton, Eva Alisic, Oliver Eastwood, and Cheney Shreve declare no conflict of interest.

Maureen Fordham has received a grant from the European Union.

Human and Animal Rights and Informed Consent This article does not contain any studies with human or animal subjects performed by any of the authors.
487

488

489

490

491

492

493

494

495

496

497

498

499

500

501

502

503

504

505

506

507

508

509

510

511

512

513

514

515

516

517

518

519

520

521

522

523

524

525

526

527

528

530

531

532

533

534

535 


\section{References}

Papers of particular interest, published recently, have been highlighted as:

- Of importance

1. Taylor AF, Kuo FE, Sullivan WC. Views of nature and self-discipline: evidence from inner city children. J Environ Psychol. 2002;22:49-63.

2. Wells NM. At home with nature: effects of 'greenness' on children's cognitive functioning. Environ Behav. 2000;32(6):775-95.

3. Kitteridge A-M, Fordham M. Flood evacuation in two communities in Scotland: lessons from European research. International Journal of Mass Emergencies and Disasters. 1998;16(2):119-43.

4. Gibbs L, Macdougall C, Mutch C, O'Connor P. Child citizenship in disaster risk and affected environments. In: Paton D, Johnston DM, editors. Disaster resilience: an integrated approach. 2nd ed. Springfield: Charles C. Thomas; 2017. p. 138-57. Chapter discusses how theory and intervention strategies should be childcentered; encompass the interdependent contributions of child, family, school and community; and do so in ways that acknowledge the rights of children to have agency in their own lives.

5. Mooney M, Tarrant R, Paton D, Johal S, Johnston D. Getting through: children's effective coping and adaptation in the context of the Canterbury, New Zealand, earthquakes of 2010-2012. Australas J Disaster Trauma Stud. 2017;21:19-30.

6. Mooney M, Tarrant R, Paton D, Johal S, Johnston D (in prep). Family elements in supporting children's effective coping with a disaster. J Child Fam Stud.

7. Zhu T, Zhang Y-J. An investigation of disaster education in elementary and secondary schools: evidence from China. Nat Hazards. 2017;89:1009-29. Survey of student and teacher perceptions of school-based disaster education in Beijing, Hunan, Guandong, and Sichuan. Key results: positive outcomes have emerged where disaster education is present; teacher's perceptions recommend training needs to be more comprehensive and location specific.

8. Gibbs L, Mutch C, Connor PO, Macdougall C. Research with, by, for and about children: lessons from disaster contexts. Global Studies of Childhood. 2013;3(2):129-41.

9. Hart R. Children's participation in planning and design. In: Weinstein CS, editor. Spaces for children. New York: Plenum; 1987. p. 217-39.

10. Hart R. Children's participation: from tokenism to citizenship, innocenti essays no. 4. New York: UNICEF; 1992.

11. Hart R. Stepping back from 'the ladder': reflections on a model of participatory work with children. In: Reid A, Jensen BB, Nikel J, Simovska V, editors. Participation and learning. New York: Springer; 2008. p. 19-31.

12. O'Kane C. Children's participation in the analysis, planning and design of programmes: guide for Save the Children staff. London: Save the Children and UNICEF; 2013. https://www.unicef.org/ adolescence/cypguide/files/Children_Participation_in_ Programming_Cycle.pdf.

13. Derr V. Louise Chawla's thoughts on children's participation - then and now. Child in the City https://www.childinthecity.org/2016/07/ 08/louise-chawlas-thoughts-on-children-in-the-future; 2016.

14. Clandinin DJ, Caine V, Lessar S, Huber J, editors. Engaging in narrative enquiries with children and youth. New York: Routledge; 2016.

15. Lundy L. 'Voice' is not enough: conceptualizing Article 12 of the United Nations Convention on the Rights of the Child. British Educational Research Journal. 2007;33(6):927-42. On child participation, describing a model involving voice, space, audience, and influence.

16. IASC (Inter-Agency Standing Committee). The gender handbook for humanitarian action. Geneva: IASC; 2018.

17. PLAN. Because I am a girl: the state of the world's girls 2013double jeopardy: adolescent girls and disasters https://planinternational.org/publications/state-worlds-girls-2013-adolescentgirls-and-disasters; 2013.

18. Fothergill A, Peek L. Children of Katrina. Austin: University of Texas Press; 2015. In-depth longitudinal study of children's recovery with excellent methodological annex

19. Kitagawa K. Continuity and change in disaster education in Japan. History of Education: Journal of the History of Education Society. 2015;44(3):371-90.

20. Yoshida Y, Takeuchi Y, Shaw R. Town watching as a useful tool in urban risk reduction. In: Shaw R, Srinivas H, Sharma A, editors. Urban risk reduction: an Asian perspective. Bingley: Emerald; 2009. p. 189-205.

21. Edington D. Reconstructing Kobe: the geography of crisis and opportunity. Toronto: UBC Press; 2010.

22. Shiwaki K, Shaw R. Community linkages and disaster risk reduction education. In: Shiwaki K, Sukurai A, Shaw R, editors. Disaster resilience of education systems: experience from Japan. Tokyo: Springer Japan; 2016. p. 91-104.

23. Shaw R, Takeuchi Y. Town watching handbook for disaster education: enhancing experiential learning Geneva: UNISDR https:// www.unisdr.org/we/inform/publications/12062; 2009.

24. Ogawa Y, Fernandez A, Yosimura T. Town watching as a tool for citizen participation in developing countries: applications in disaster training. International Journal of Mass Emergencies and Disasters. 2005;23(2):5-36.

25. Wisner B. Let our children teach us. Geneva: UNISDR; 2006. https://www.unisdr.org/we/inform/publications/609

26. Ronoh S, Gaillard JC, Marlowe J. Children with disabilities in disability-inclusive disaster risk reduction. Policy Futures in Education. 2017;15(3):380-8.

27. Honkanen K, Poikolainen J, Karlsson L. Children and young people as co-researchers - researching subjective well-being in residential area with visual and verbal methods. Children's Geographies. 2017;16(2):184-95.

28. United Nations Office for Disaster Reduction (UNISDR). The Sendai framework for disaster reduction. New York, United Nations https://www.unisdr.org/we/coordinate/sendai-framework; 2015.

29. Mitchell T, Haynes K, Hall N, Choong W, Oven K. The roles of children and youth in communicating disaster risk. Children, Youth and Environments. 2008;18(1):254-79.

30. Tanner T. Shifting the narrative: child-led responses to climate change and disasters in El Salvador and the Philippines. Child Soc. 2010;24(4):239-351.

31. Rich H, Kelman I. School emergency risk training in Puebla, Colorado, USA. In: Sensara SR, Sarkar A, editors. Disaster risk management. New Delhi: Concept Publishing; 2013. p. 58-84.

32. Mort M, Walker M, Williams A, Bingley A. From victims to actors: the role of children and young people in flood recovery and resilience. Environment and Planning C: Politics and Space. 2017;36(3):423-42. In-depth research with two groups of flood-affected children and young people following a series of devastating storm events in England reveals that children and youth are impacted by flooding in unique ways. Children developed flood manifestos for change to better communicate how their needs can be better supported during disaster, and demonstrating their capabilities to engage and contribute to flood policy.

33. Fothergill A. Children, youth, and disasters In: Cutter S, editor Oxford research encyclopedia of natural hazard science, published
598 
664

665

666

667

668

669

670

671

672

673

674

675

676

677

678

679

680

681

682

683 on line http://naturalhazardscience.oxfordre.com/view/10.1093/ acrefore/9780199389407.001.0001/acrefore-9780199389407-e23; 2017.

34. Ronan KR, Haynes K, Towers B, Alisic E, Ireland N, Amri A, et al. Child-centred disaster risk reduction: can disaster resilience programs reduce risk and increase the resilience of children and households? Australian Journal of Emergency Management. 2016;31(3): 49-58. Overviews child-centered disaster risk reduction (CCDRR). Key challenges: lack of evaluation of different CC-DRR initiatives and patchy implementation. Key recommendations: researchers partnering with management agencies, schools, and federal departments. School-wide use of the CC-DRR resource was found to be the strongest facilitator for implementation and a lack of awareness of the resource was found to be the strongest deterrent.

35. Amri A, Haynes K, Bird DK, Ronan, K. Bridging the divide between studies on disaster risk reduction education and child-centred disaster risk reduction: a critical review. Children's Geographies. published on line https://doi.org/10.1080/14733285.2017. 1358448; 2017.

36. Pfefferbaum B, Pfefferbaum RL, Van Horn R. Involving children in disaster risk reduction: the importance of participation. Eur $\mathrm{J}$ Psychotraumatol 2017;9. published on line https://www. tandfonline.com/doi/full/10.1080/20008198.2018.1425577.

37. Dich N, Hansen AM, Avlund K, Lund R, Mortensen EL, Bruunsgaard H, Rod NH. Early life adversity potentiates the effects of later life stress on cumulative physiological dysregulation. Anxiety Stress Coping. 2015. Paper discusses how disasters to create prolonged disruptions to family and support networks can produce repercussions throughout childhood development and on into adult lives.

38. Osofsky HJ, Osofsky JD. Lessons learned about the impact of disasters on children and families and post-disaster recovery. In: Culp AM, editor. Child and family advocacy: bridging the gaps between research, practice, and policy. New York: Springer; 2013. p. 91105.

39. Masten AS, Obradovic J. Disaster preparation and recovery: lessons from research on resilience in human development. Ecol Soc. 2008;13:1. published on line http://www.ecologyandsociety.org/ vol13/iss $1 /$ art9/

40. La Greca AM, Lai BS, Joorman J, Auslander BA, Short MB. Children's risk and resilience following a natural disaster: genetic vulnerability, posttraumatic stress, and depression. J Affect Disord. 2013;151:860-7.

41. Sriskandarajah V, Neuner F, Catani C. Parental care protects traumatized Sri Lankan children from internalizing behavior problems. BMC Psychiatry. 2015;15:203. https://doi.org/10.1186/s12888015-0583-X.

42. Uttervall M, Hultman CM, Ekerwald H, Lindam A, Lundin T. After the flood: resilience among tsunami-afflicted adolescents. Nord J Psychiatry. 2014;68(1):38-43.

43. King LS, Osofsky JD, Osofsky HJ, Weems CF, Hansel TC, Fassnacht GM. Perceptions of trauma and loss among children and adolescents exposed to disasters a mixed-methods study. Curr Psychol. 2015;34(3):524-36.

44. Grych J, Hamby S, Banyard V. Psychology of violence the resilience portfolio model: understanding healthy adaptation in victims of violence. Psychology of Violence. 2015;5(4):343-54.

45. Cobham VE, McDermott B. Perceived parenting change and child posttraumatic stress following a natural disaster. J Child Adolesc Psychopharmacol. 2014;24(1):18-23.

46. Howell KH, Barrett-Becker EP, Burnside AN, Wamser-Nanney R, Layne CM, Kaplow JB. Children facing parental cancer versus parental death: the buffering effects of positive parenting and emotional expression. J Child Fam Stud. 2016;25(1):152-64.
47. Pfefferbaum B, Noffsinger MA, Wind LH, Allen JR. Children's coping in the context of disasters and terrorism. J Loss Trauma. 2014;19:78-97.

48. Poulsen KM, McDermott BM, Wallis J, Cobham V. School-based psychological screening in the aftermath of a disaster: are parents satisfied and do their children access treatment. J Trauma Stress. 2015;28(2):69-72.

49. Banks DM, Weems CF. Family and peer social support and their links to minority youth. Am J Orthopsychiatry. 2014;84(4):341-52.

50. Kerns CE, Elkins RM, Carpenter AL, Chou T, Greif J, Comer JS. Caregiver distress, shared traumatic exposure, and child adjustment among area youth following the 2013 Boston Marathon bombing. J Affect Disord. 2014;167:50-5.

51. MacPhee D, Lunkenheimer E, Riggs N. Resilience as regulation of developmental and family processes. Family Relations: Interdisciplinary Journal of Applied Family Studies. 2015;64: 153-75. Paper discusses how effective parental coping can, through teaching or modelling effective and flexible coping skills, facilitate children's adaptive capacity, re-establish their sense of safety, reduce anxiety, and increase their self-efficacy and sense of connectedness.

52. McNeill IM, Ronan KR. Children in disasters: the role of household preparedness. Nat Hazards. 2017;89:1239-54.

53. Borelli JL, Crowley MJ, David DH, Sbarra DA, Anderson GM, Mayes LC. Attachment and emotion in school-aged children. Emotion. 2010;10(4):475-85.

54. Wooding S, Raphael B. Psychological impact of disasters and terrorism on children and adolescents: experiences from Australia. Prehosp Disaster Med. 2004;19(1):10-20.

55. Bai S, Repetti RL. Short-term resilience processes in the family. Fam Relat. 2015;64(1):108-19.

56. Hakvoort EM, Bos HMW, van Balen F, Hermanns JMA. Family relationships and the psychosocial adjustment of school-aged children in intact families. J Genet Psychol. 2010;171(2):182-201.

57. Carpenter AL, Elkins RM, Kerns C, Chou T, Greif Green J, Comer JS. Event-related household discussions following the Boston Marathon bombing and associated posttraumatic stress among area youth. J Clin Child Adolesc Psychol. 2017;46(3):331-42.

58. Heath SE, Kass PH, Beck AM, Glickman T. Human and pet-related risk factors for household evacuation failure during a natural disaster. Am J Epidemiol. 2001;153(7):659-65.

59. Trethowan V, Nursey J. Helping children and adolescents recover from disaster: a review of teacher-based support programs in Victorian schools. The Australian Journal of Emergency Management. 2015;30(4):17.

60. Eifling K, Moy P. Evidence-based EMS: psychological first aid during disaster response. What's the best we can do for those who are suffering mentally? EMS World. 2015;44(7):32-4.

61. Dieltjens T, Moonens I, Van Praet K, De Buck E, Vandekerckhove P. A systematic literature search on psychological first aid: lack of evidence to develop guidelines. PLoS One. 2014;9:12. published on line https://www.ncbi.nlm.nih.gov/pmc/articles/PMC4264843/. Systematic review regarding psychological first aid, concluding that the scientific literature on PFA does not provide evidence regarding its effectiveness.

62. Vernberg EM, Hambrick EP, Cho B, Hendrickson ML. Positive psychology and disaster mental health: strategies for working with children and adolescents. J Clin Psychol. 2016;72(12):1333-47.

63. Hobfoll SE, Watson P, Bell CC, Bryant RA, Brymer MJ, Friedman $\mathrm{MJ}$, et al. Five essential elements of immediate and mid-term mass trauma intervention: empirical evidence. Psychiatry: Interpersonal and Biological Processes. 2007;70(4):283-315.

64. Pfefferbaum B, Nitiéma P, Tucker P, Newman E. Early child disaster mental health interventions: a review of the empirical evidence. Child Youth Care Forum. 2017:46(5):621-42. Paper discusses need to research both children's trauma and their adaptive 
responses, and to do so in ways that accommodate how the parental, social, and environmental contexts in which they live influences adaptation, coping, and distress in post-disaster situations.

65. Cicchetti D. Annual research review: resilient functioning in maltreated children - past, present, and future perspectives. J Child Psychol Psychiatry. 2013;54(4):402-22.

66. Weems CF, Graham R. Resilience and trajectories of posttraumatic stress among youth exposed to disaster. J Child Adolesc Psychopharmacol. 2014;24(1):2-8.
67. Gil-Rivas V, Kilmer RP. Children's adjustment following Hurricane Katrina: the role of primary caregivers. Am J Orthopsychiatry. 2013;83(2, 3):413-21.

68. Bronfenbrenner U, Morris PA. The bio-ecological model of human development. In: Lerner RM, Damon W, editors. The handbook of child psychology, Vol 1: theoretical models of human development. 6th ed. Hoboken: Wiley; 2006. p. 793-828. 